of men in scientific work in case an attempt were made to enforce the rule. He believed, however, that the rule would be ignored by the majority of workers. Regarding the principle of tautonomy, he expressed himself not only as not opposed to it but as highly in favor of it, and he himself has decided to purposely introduce tautonimic names whenever the occasion presents itself. By use of tautonomy, the type species of a genus is shown in its name; without tautonomy, it is necessary to refer to the literature in order to recall the type species.

He did not believe it possible to enforce the rule concerning the list of excepted names. In fact, this rule did not seem to mean very much to him, as the congress had failed to determine the types for the names which were excepted and had apparently failed to provide for cases in which the genera in question might be defined in the future.

He recognized the delicacy of the situation which now faces the American botanists, but it seemed to him that the botanical code contained so many subjective elements that it was impossible for this code to expect to have a very long life. It has been the history of nomenclature since the time of Linnaeus that rules based on subjective ideas were shortlived. A rule in nomenclature must be objective if we expect it to be accepted generally and if we expect it to be permanent. Discussion followed by Dr. Gill.

The last paper on the program was by Dr. Hugh M. Smith on the 'Sargassum Fish,' a tropical species of the southern Atlantic occasionally brought by winds and currents to more northern shores. A large number of the fish were taken at Woods Holl and vicinity. The eggs from these prove to be entirely different from those described by Agassiz and long supposed to have belonged to the sargassum fish. Specimens of the fish were shown and a beautiful painting of it by C. R. Knight, showing its wonderful protective coloration. The paper was discussed by Dr. Gill.

Vernon BaILEY, Recording Secretary, pro tem.
DISCUSSION AND CORRESPONDENCE.

ONTOGENETIC SPECIES AND OTHER SPECIES.

REFERRING to the admirable article in SoIENCE (November 24, 1905, p. 661) on 'The Evolution of Species through Climatic Conditions,' by Dr. J. A. Allen, I may once more gratefully recognize my own especial indebtedness to Dr. Allen's pioneer investigations of thirty years ago in this particular direction. These studies have been epoch-making in the history of ornithology.

It remains, however, to be determined whether these environmental forms-these species and subspecies produced by the direct influence of heat, cold, humidity and aridity -are 'ontogenetic species' (a term originating, so far as I know, with Professor V. L. Kellogg) or whether they have a real existence outside the lifetime of the individuals actually composing the group or species. We do not know which of the traits induced by direct section of the environment, if any, are actually hereditary and which are not. If we find that the dusky woodpeckers of Vancouver Island retain this shade when reared in Arizona, then humidity would be a real factor in the formation of species. If such birds, transferred in the egg to a new region should develop in the fashion of the local race of this region, and not like their own parents, then the duskiness is not a true specific or subspecific character. The real character of the species would be found in the tendency to develop dark plumage in humid surroundings and pale feathers under other conditions. In such case humidity would be merely a factor modifying individual development but not connected with the origin of species.

It may be that these questions have been already solved by experiment on birds, but if so, the experiments have escaped my attention. Eggs of the woodpeckers, chickadees and other birds showing dusky phases should be hatched in the arid plains. The red-shafted flicker of California should be bred in New England, and the permanence of the difference between large birds of northern range and their smaller southern homologues should be tested. 
An 'ontogenetic species' its traits produced by the direct action of the environment, is the Loch Leven trout ('Salmo levenensis'), which I have lately discussed in these columns. Transferred to the brooks of England or to those of California, this supposed species loses its lake-bred characters and becomes the common brook trout.

Perhaps our ornithologists will some day test their species and subspecies by a test of the permanence of this class of characters. No doubt we should drop from the systematic lists all forms which may prove to be purely ontogenetic, all whose traits are not fixed in heredity.

In my recent article, as noticed by Dr. Allen, I have used the word 'barrier' a little too vaguely. For the purposes of this study, I should regard a broad plain as a barrier to a species which inhabits it, even though it were abundant, from one side to the other. A barrier in this sense is anything whatever which checks free interbreeding, even though it offers no actual check to the life or movement of the species. With quiescent animals, the individual moves but a short distance and the traits at one end of an unbroken series may be quite different from those of other individuals at the farther end, as Dr. Allen has very properly suggested. The term 'bionomic barrier,' used by Dr. A. E. Ortmann in a personal letter, seems to me a very apt one as covering the species-producing phases of isolation.

- Certain papers of Rev. John T. Gulick on the evolution of species of land-snails and other animals deserve more attention than they have received. In, one of these papers, 'Divergent Evolution through Cumulative Segregation' (Smithsonian Report for 1891, p. 273), Mr. Gulick corrects certain erroneous assumptions on the part of Dr. Moritz Wagner. Mr. Gulick says:

Separate generation is a necessary condition for divergent evolution but not for the transformation of all the survivors of a species in one way.

Separation does not necessarily imply any external barriers or even the occupation of separate districts.

Diversity of natural selection is not necessary to diversity of evolution.
Difference of external conditions is not necessary to diversity of erolution.

Separation and variation-that is, variation not overwhelmed by crossing-is all that is necessary to secure divergence of type in the descendants of one stock, though external conditions remain the same and though the separation is other than geological. The separation I speak of is anything in the species or the environment that divides the species into two or more sections that do not freely intercross, whether the different sections remain in the original home or enter new and dissimilar environments.

All of this is in general accord with my own experience.

David StarR Jordan.

\section{ORTHOGENETIC VARIATION?}

IN a recent paper ${ }^{1}$ I repiewed Gadow's hypothesis of 'Orthogenetic Variation,'" in the light of his own evidence, and in the light of such observations as could be added. In Science for November 7, 1905, Dr. Gadow publishes a reply under the title 'Orthogenetic Variation.' It would be superfluous merely to rediscuss the data previously published; in fact, had the matter gone no further than the original paper, elaborate criticism in the first instance might have been unnecessary, since scientific readers could judge the evidence for themselves. But unfortunately, as will be shown below, subsequent use has been made of the idea for presentation to the general public, not expressly as a tentative hypothesis -but without qualification.

In the first paragraph of his reply, Gadow says, 'I am anxious that it [orthogenetic variation] should not be misrepresented,' and, in the second paragraph, "the paper by $\mathrm{Mr}$. Robert E. Coker *** calls for some remarks on my part by way of protest and correction.' I was glad that after careful reading of his paper, I found no reference to any statement

. ${ }^{1}$ Gadow's hypothesis of 'Orthogenetic Variation in the shells of Chelonia,' Johns Hopkins University Circular, No. 178, May, 1905.

2 'Zoological Results Based on Material from New Britain, New Guinea, Loyalty Islands and elsewhere, collected during the years 1895, 1896 and 1897, by Arthur Willey' Part III., pp. 207-222, Pl. XXIV., XXV., Camb. Univ. Press, May, 1899. 